\title{
So the difference is what?
}

\section{S Hancocks, OBE*}

\section{Trying to explain the difference between NHS and Private can sometimes be a bit of a trial....}

$\mathbf{T}^{\mathrm{t}}$ all seems fine to begin with. You have 1 decided that enough is enough. Out with the non-profitable NHS and in with the new Independent or Private or Insurance based system.

The marketing blurb seems such a doddle too. The fancy leaflets that you have had designed look so very good, especially the soft-focus shots of your receptionist lovingly pencilling in another appointment while holding the phone in the crook of her neck and neatly rearranging the petals of the hydrangea display with the other. Then there are those lines of seductive phraseology about understanding the patient's needs in an oral healthcare setting with special emphasis on aesthetic premium and health based mutuality. The words practically slide off the glossily laminated card like composite off a Teflon coated instrument.

It is not until you get face to face with the patient that you start to have to question your own values a bit more thoroughly. In fact, with this potential danger in mind, you decide to have a dry run with your dental nurse as the patient. Role play, very a la mode. The receptionist shows her in as if she was a real patient, with the pair of them trying their utmost not to giggle out loud.

'Good morning Mrs Brunswick, as you may have heard, we are moving towards a private fees system and I'd like to explain it to you'.

'So it's going to cost more then?' Megan is straight into this acting stuff in a big way.

'Not necessarily, no.' You didn't anticipate going off down this line quite so soon but luckily remember that key word 'standards' from the PR man who did the brochures. 'What it will mean is a general raising of standards', you smile positively.

'So, the standard will rise?'

'Oh yes.' You're back on track now. 'Well, yes. We here at Sunnyside Practice...' an unexpected further interruption.

'So, what I've been getting up to now is a poor standard?' Megan cuts into your flow rather alarmingly.

'No, it will all be the same. Clinically.'

'So there's no advantage then?'
'Yes, there's an advantage because, for example, I might use better quality materials.' Quality, another of those saving-grace PR terms. Phew, just in the nick of time. But you're fatally off your guard, swooning in the glory of recovery.

'Better than before?' Megan is in the groove now.

'Yes. Definitely.'

'So I've been getting sub-standard materials as well as a lower service level, is that what you're saying?

'No. No, not at all. That is, they've been adequate for the job in hand.'

So what you're really saying is that currently you are not spending enough time with me, you're offering a poor service and using a lower quality of materials and techniques?'

\section{'But not the best available?'}

'No, I mean, yes.' Oh dear, it's starting to go downhill rapidly. You try and apply the brakes and remember that other piece of essential inter-personal advice, and look Megan straight in the eye. 'What I'm trying to say is that I will be able to spend more time with you, attending to your individual needs and requirements.'

'So you haven't been spending enough time on me either?'

You now have a sneaking suspicion that Megan has visited the website of a consumer advice service the previous evening. 'Yes. No. Well, as much time as I could afford.'

'Which might not have been enough?'

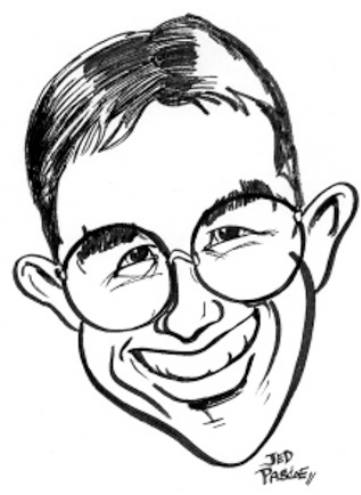

'Well yes, clinically it was enough.' 'Clinically?'

'Yes, in order to get the job done.'

'As quickly as possible.'

'Yes. No.' You really wish you'd used an ordinary patient after all, surely they aren't going to be this stroppy in real life? 'When I say as much time as I could afford what I mean is as profitably as possible.' The words freeze in your mouth as you form them but gallop out before you can swallow them back.

'So this is just about money after all then?' Megan scowls just like she does when you ask her to mix another bowl of alginate because you didn't manage to load the last one fast enough.

'No. Yes. Well, it's difficult to explain.' You gather together all your remaining firepower for a final assault. 'I will be able to provide you with a better service, taking more time and using a higher quality of materials and techniques,' Megan looks slightly subdued and you start to feel a bit more confident, 'so that the standard of your experience as a valued customer will rise concomitantly.' Concomitantly, wow, where did that come from? That's bound to have silenced any resistance and ensured a conversion. You smile at Megan.

She grins back. 'So what you're really saying is that currently you are not spending enough time with me, you're offering a poor service and using a lower quality of materials and techniques and have been palming me off for the last eight years with a rushed and substandard service in the guise of a caring professional only concerned with my interests when it has in fact been guided entirely by the profitability of your somewhat shaky business?'

'So that's a 'no' then?' You half smile.

Megan, completely in the spirit of the exercise, gets up out of the chair but turns back into herself as she marches towards the door, 'Frankly I think you need a better publicist. I suggest that I talk this through with the patients before they get in here. Just stick to what you do best eh? Clinically.

* The author is commissioning editor for the BDJ. 